\title{
Debilidade mental e psicose na trança do RSI: um caso clínico ${ }^{1}$
}

\section{Mental debility and psychosis in the RSI' braid: a clinical case}

\author{
Luis Flávio Silva Couto* \\ Pontifícia Universidade Católica - PUC/MG, Belo Horizonte, Minas Gerais, Brasil
}

\begin{abstract}
RESUMO
Neste trabalho, propõe-se a leitura de um caso clínico, tomando-se por base as configurações do nó borromeano e das tranças, tal como propostos por Fabien Schejtman. Com pouco mais de sessenta anos, o paciente recebera, quando criança, o diagnóstico de retardo mental. Para nós, entretanto, trata-se de uma psicose ordinária sem fenômenos elementares, suplementada por uma debilidade mental. No texto, tecemos considerações sobre essa suplência que a debilidade mental faz ao lapso do simbólico em sua relação com o real, do ponto de vista das elaborações tanto dos nós, quanto das tranças. Mostramos não somente a configuração da trança antes de o paciente ser tratado por um praticante de psicanálise, como também a mudança de configuração que vem ocorrendo agora.
\end{abstract}

Palavras-chave: Debilidade mental, psicose ordinária, nó borromeano.

\begin{abstract}
This paper is about one clinic case, based on the borromeanean knot configurations and on the braid configurations, as proposed by Fabian Schejtman. The paciente is presently a little over sixty years old and he has been diagnosed as mentally retarded since he was a child. We understand, however, that his is a case of ordinary psychosis generally without elementary phenomena. It is also supplemented by feeble-mindedness. In the text we refer to the way feeble-mindedness supplements the symbolic lapse, considering its association to the real, and based on the knot configurations as well as on the braid configurations. These configurations are studied here both before Edimundo`s treatment and during his present applied psychoanalysis.
\end{abstract}

Keywords: Mental debility, ordinary psychosis, borromeanean knot.

\section{I ntrodução}

O programa de investigação convocado a abordar a clínica a partir das psicoses ordinárias procura estabelecer uma certa pragmática, caso a caso, de como em um sujeito vêm a se constituir as consistências do real, do simbólico e do imaginário; como 0 sujeito vem a interpretar os acontecimentos do corpo que Ihe chegam; como situa a fuga do sentido; como lida com a dispersão do imaginário na 
desmembração fundamental; e como trata de recorrer então a normas mais ou menos estabelecidas para apoiar-se na construção de algo (LAURENT, 2006, tradução nossa). ${ }^{2}$

\subsection{Relato do caso}

Edimundo (nome fictício) tem pouco mais de sessenta anos e frequenta a Clínica de Psicologia da PUC Minas desde o primeiro semestre de 1995, por demanda espontânea. Desde junho de 2007, é atendido na abordagem psicanalítica. Nos registros, consta ser portador de retardo mental, diagnosticado em uma escola especializada em Belo Horizonte, e paciente psiquiátrico num posto de saúde, fazendo uso de Diazepan, Haldol e medicação para hipertensão arterial.

Em sua análise, Edimundo diz que precisa falar, desabafar e ter sua fala respeitada. Enquanto casado (de 1987 a 2003), não tinha lugar nem apoio em casa. Quer recuperar a tranquilidade e sair da depressão. Com o falecimento da esposa em 2003, volta a morar com a mãe e com os irmãos. Queixa-se de que ser analfabeto impede sua evolução profissional. Em fevereiro de 2001, um laudo da psicóloga de uma escola especial dizia: "apresenta dificuldades para a alfabetização, tem escolaridade primária e cursa o Mobral à noite na referida instituição".

A história clínica aponta um sofrimento constante por não ser reconhecido, pois, segundo seu relato, "é um homem direito" honesto, trabalhador; o único homem direito e digno de confiança que existe no mundo. Segue os ensinamentos de sua mãe, ajuda a todos e nunca foi ajudado. Conforme salienta, foi ela quem o teria ensinado a ser o homem direito. A partir dos quatorze anos, diz ter sempre trabalhado para sustentar a família, na maioria das vezes como servente de pedreiro. Não pôde estudar, ter uma profissão, ou mesmo uma aposentadoria que Ihe assegurasse a vida. Revolta-se com as dificuldades que o impedem de ter um emprego fixo, isto é, de exercer o papel de homem direito.

Tangente ao seu nervosismo, relata uma primeira crise de agitação na infância que o levou a um médico que lhe receitou Lorax. A segunda crise aconteceu aos vinte anos e culminou em uma nova internação num hospital psiquiátrico. Sente-se em uma eterna servidão, sendo explorado pelos irmãos. Revela que não teve infância. O padrasto impedia-o de brincar na rua por medo de que ele fizesse algo errado. Desde que adquiriu o próprio dinheiro (aos quatorze anos), frequenta a zona de meretrício de Belo Horizonte e diverte-se com as "mulheres da vida". Segundo ele, elas são honestas, nervosas, e às vezes manifestam a vontade de morar com ele. Elas o amam porque, sendo um homem direito, é capaz de cuidar 
do dinheiro delas: faz serviços bancários, como depósitos e retiradas. Elas têm sorte, afirma, pois nenhum outro faria o que ele faz.

Para ele, a vida é difícil e poderia ter sido diferente caso tivesse se formado como os irmãos. Trabalhando desde os quatorze anos, não Ihe foi dada a oportunidade de estudar. Quer aprender a ler, a escrever e a contar, a fim de viabilizar a conquista de um emprego melhor. Estudou em escolas especiais à noite, mas nunca passa de ano, pois não consegue frequentar as aulas. Fala da felicidade de sua juventude, quando tinha um corpo forte e emprego com carteira assinada. Hoje pensa em se aposentar pelo INSS, embora goste de trabalhar.

Atualmente, tem uma namorada em um bordel e pretende "morar com ela" quando conseguir uma renda fixa para sustentá-la, retirando-a da "vida" de prostituição. Considera-se o único homem corajoso o suficiente para tirar qualquer mulher dali. Ele encarna a posição daquele que põe ordem na zona, conhecendo a fundo o que ali acontece. Recorda-se de que, certa noite, em uma data não muito precisa, 1976 ou antes, quando estava saindo do bordel, chegou um "homem da lei" e pediu-lhe os documentos de identidade. Como não portava a carteira de trabalho, foi preso por uma semana. Ficou traumatizado por sua família desconhecer seu paradeiro (não foi possível averiguar a veracidade desse relato, nem ele conta como saiu de lá). Um ano depois, esteve internado em um hospital psiquiátrico porque apresentava um alto grau de agitação. Afirma que ficara agitado pela dificuldade de arrumar emprego. No início dos anos 80, buscou apoio psicológico em função do trauma surgido em decorrência de sua prisão. Voltou a frequentar os bordéis e, nessa época, conseguiu um emprego de faxineiro com carteira assinada.

Em relação a esse seu confronto com a lei e sua prisão, não se tem certeza de que isso de fato tenha ocorrido, ou se se trata de um episódio delirante momentâneo, determinado pela posição débil. 0 que importa assinalar, entretanto, é a sua inabilidade, na época, em lidar com o fato, tenha ele realmente ocorrido ou não. Muito de suas dificuldades vividas a partir dos anos 80 é atribuído a essa incapacidade de lidar com a lei, com a autoridade policial que supostamente o teria prendido. Tal debilidade encontra-se em consonância com o diagnóstico pedagógico: dificuldade de aprendizagem; retardo mental.

$\mathrm{Na}$ clínica, ele repete continuamente as mesmas "queixas". O tempo passa e os personagens não mudam. Ele não problematiza e nem faz enigma, insistindo em contar sua história sem, no entanto, elaborar qualquer construção acerca disso. Qual o sentido dessa repetição? 


\subsection{Comentário do caso}

Em várias sessões Edmundo, de forma inesperada e incessante diz, no meio de uma fala, que é "um homem direito". Qual o sentido da repetição desse significante abrupto que permeia todo o seu relato? Poderíamos considerar aqui a presença do que Lacan aponta como um significante sozinho (S1) desvinculado da cadeia simbólica, um ponto sem elaboração e dito de forma inesperada e sem significado? Poderíamos ter aqui o significante S1 "em sua solidão" tal como discutido por Laurent (1995, p. 120)? Essa fala estereotipada estaria apontando de forma dramática a carência crucial do Falo simbólico $(\mathrm{PHI}=$ zero $)$, um distúrbio de linguagem, uma discordância com a linguagem comum? Teria uma "significação que basicamente só remete a ela própria, permanecendo irredutível", tal como proposto por Lacan (1955-1956/1985, p. 43) em seu seminário sobre as psicoses?

Em outras palavras, teria ele uma estrutura psicótica? Em caso afirmativo, pode-se constatar que não se trata de uma dissociação esquizofrênica, na qual o 'não sentido' impera, nem de uma psicose paranoica do tipo de Schreber (FREUD, 1911/1977), com a riqueza extraordinária de suas convicções delirantes. Também não é o caso de uma psicose de um "ser a três", tal como proposto por Elisa Alvarenga (2002) em relação à personagem Lol V. Stein, do romance O deslumbramento (DURAS, 1986).

Consideramos Edimundo psicótico, mas ele não apresenta fenômenos elementares. Sua psicose, suplementada pela debilidade mental, pode ser considerada como uma psicose ordinária, diagnosticada desde a infância como "Retardo Mental" pelos pedagogos da escola especializada onde estudou sem alcançar a alfabetização.

Tal proposta encontra-se em consonância com as conversações realizadas pela Associação Mundial de Psicanálise (AMP), entre 1996 e 1998, sobre casos raros, os chamados "inclassificáveis na clínica psicanalítica". Esses, por não se ancorarem na metáfora paterna, não conseguem estabelecer uma relação estável com o Outro. No último desses encontros, realizado em Antibes (IRMA, 1999), foi proposta uma categoria clínica, a das chamadas "psicoses ordinárias", ou "psicoses não desencadeadas". Nessa convenção, Miller refere-se à história da psicanálise e, mais particularmente, à de Schreber, dizendo que as psicoses extraordinárias sempre atraíram a atenção. Entretanto, há também os psicóticos mais modestos, os que estão em uma espécie de média: "a psicose compensada, a psicose suplementada, a psicose não desencadeada, a psicose medicada, a psicose em terapia, a psicose em análise, a psicose que evolui, e a psicose sinthomática" (MILLER, 1999, p.230, tradução nossa) ${ }^{3}$. A essas, acrescentamos também as chamada psicoses 'não sinthomáticas'. Para compreendermos o conceito, é necessário supor 
que a trança que articularia o nó borromeano tenha sofrido um erro ou lapso, como veremos adiante.

Para situarmos o campo das psicoses sinthomáticas e não sinthomáticas, podemos começar pela compreensão do que vem a ser o nó borromeano. Nos finais de seu último ensino, Lacan vai se afastando dos chamados "quatro discursos em psicanálise", e passa a trabalhar com a topologia dos nós utilizando, para isso, o brasão dos Borromeus (LACAN, 1971-1972/2010a). No caso do brasão, Lacan mostra que é somente por causa do terceiro pedacinho de barbante que os aros mantêm-se unidos. Nomeando o brasão como nó, Lacan afirma que ele é "uma cadeia de três, que, a desatar um dos anéis dessa cadeia, os dois outros não podem, nem por um só instante, manter-se juntos" (LACAN, 1971-1972/2010b, tradução nossa ${ }^{4}$.

No Seminário 22, R.S.I., (1974-1975/2010c) Lacan já associa o nó aos três registros, e afirma que os nós implicam "três indicações de sentido, de sentido materializado que se figura nas nominaçoes do simbólico, do imaginário e do real" (LACAN, 1974-1975/2010c, tradução nossa) ${ }^{5}$.

Em termos de construção prática, Lacan passa o aro imaginário por sobre o real e o simbólico por cima do imaginário, mas, ao mesmo tempo, por baixo do real, tal como apresentado na figura 1:

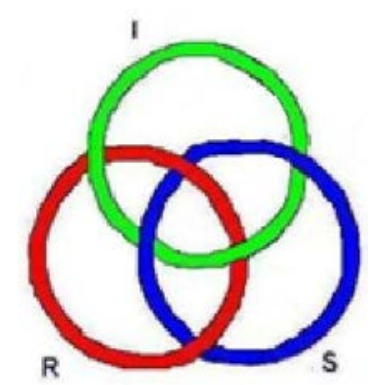

Figura 1 - 0 nó borromeano

Fonte: LACAN, 1975/ 2010c, p. 20 (modificado)

Esse modelo do nó está apresentado em uma perspectiva de sua projeção no plano (sentido sincrônico). Se pensarmos em termos de constituição do sujeito, podemos considerar que o nó não se dá na realidade psíquica de pronto. Ele é construído por meio de vários enlaçamentos do real, do simbólico e do imaginário na infância do sujeito. Isso significa que se pode tomá-lo por uma perspectiva diacrônica. Lacan aponta tal caminho ao dizer, no seminário 21 (Os não-tolos erram), que o nó borromeano, tomado por alguém pelas vias matemáticas, será agora visto não no nível dos nós, mas das tranças (LACAN, 1972-1973/2009).

O que é então uma trança? Ele se pergunta. Respondendo, diz que ela tem relação com o número três: um, dois, três. Sem isso, não se chamaria uma trança. Questiona: como fazer, com esses três, uma 
trança? Um tanto cômico, diz que os que se ocupam com os cabelos de uma mulher sabem fazê-la. Em seguida, diz que a trança se faz colocando o dois no lugar do um, permanecendo o três em seu lugar:

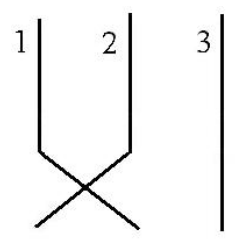

Figura 2 - 0 início de uma trança

Fonte: LACAN, 1972-1973/2009

Vinculando a trança ao nó, Lacan continua a trançar e, mostrando como se faz uma com seis cruzamentos, demonstra que o nó borromeano daí resulta. Em seguida, convida o auditório a fazer a tentativa de construí-lo.

\subsection{Sobre tranças e nós}

Tomando o lapso como uma falha significante (LACAN, 19751976/2007, p.144) em um dos cruzamentos da trança do real, do simbólico e do imaginário, pode-se considerar como puramente ideal o nó borromeano sem lapsos, seja no sentido de uma trança aberta, seja no de uma trança fechada, como no brasão dos Borromeus. Não penso que alguém consiga, em sua construção subjetiva, não produzir um lapso sequer no enlaçamento entre o real, o simbólico e o imaginário.

Em seu livro A criança na clínica psicanalítica, Ângela Vorcaro (2004) explicita os seis movimentos da constituição da trança infantil ideal de forma bastante didática. Começa supondo um ponto zero e mítico que precederia o início do trançar na criança, dando-lhe a condição de possibilidade de existência. Trata-se do lugar simbólico onde a mãe do recém-nascido vem inseri-lo enquanto organismo real. Isso equivaleria ao termo simbólico que o situava no campo discursivo antes que nascesse. Vorcaro (2004, p.16) aponta que essa superposição do real do organismo na posição simbólica possibilita uma espécie de regularidade automática de alternância dos estados de tensão e apaziguamento, que se constitui como a matriz simbólica inaugural da condição de subjetivação. É esse construto teórico que Ihe possibilita apontar o organismo como real, a alternância entre tensão e apaziguamento como simbólica e a consistência dos sentidos em que o agente materno interpreta o organismo como imaginária. Estariam aí as três linhas maleáveis, R. S. I., que tecem, organizam e deformam, com o passar do tempo, a trança da subjetividade humana. 
Por não ter espaço para maiores considerações sobre a amarração ideal da criança, aponto apenas os seis cruzamentos que sustentam a condição mínima de uma posição simbólica estrutural, na sequência de amarração proposta pela autora:
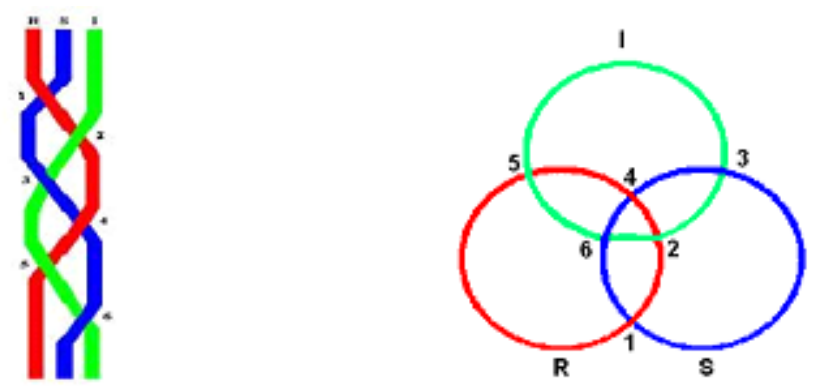

Figura 3 - Os seis cruzamentos da trança borromeana e o nó borromeano fechado Fonte: VORCARO, 2004, p.16

1. A fissura real incide no simbólico.

É o funcionamento simbólico, presidido pelo movimento que articula tensão e apaziguamento;

2. O imaginário recobre a hiância real no simbólico.

A criança se ressente da alteridade materna, nela localizando a possibilidade da satisfação plena anterior. Com isso, a falta real no simbólico é recoberta com a imaginarização do agente materno.

3. Demarcação simbólica do imaginário.

A criança propõe-se como falo, tentando determinar o desejo materno, encarnando-se como termo simbólico que equaciona a falta pressentida na mãe. Entretanto, oferecer-se como falo ao desejo materno é fazer-se de objeto e anularse como desejante.

4. A fissura real da equivalência simbólica criança $=$ falo.

A criança pressente que essa posição de signo não se sustenta. Por mais que a criança se dê, ela não é o falo materno, não satisfaz a mãe. Com isso, depara-se com algo de real que priva e interdita a mãe, criando um obstáculo intransponível entre ela e sua mãe.

5. O encobrimento imaginário da interdição real.

Esse obstáculo será transformado pela criança no mito da onipotência paterna: ou seja, a impossibilidade real de ser o objeto do gozo materno é reencontrada, imaginariamente, personificada em pai que, apesar de terrível, por Ihe tirar a mãe, defende-a da voracidade materna ilimitada.

6. O laço da metáfora - o simbólico incide no imaginário.

Aqui, produz-se a metáfora paterna, momento em que o simbólico ultrapassa o imaginário. A criança encontra o termo simbólico que barra a sua posição de equivalência fálica e cria o título virtual que sustentará a sua identificação ao elemento mediador do campo simbólico que estrutura a orientação da relação à alteridade.

\subsection{0 nó borromeno e o sinthoma borromeano}

Tal configuração constitui o que considero uma amarração ideal, e Lacan (1974-1975/2010c) sugere que ela pode falhar em um ou dois 
pontos. Tais falhas, chamadas de lapsos ou erros, apontaram-lhe a necessidade da passagem do nó de três termos para o de quatro.
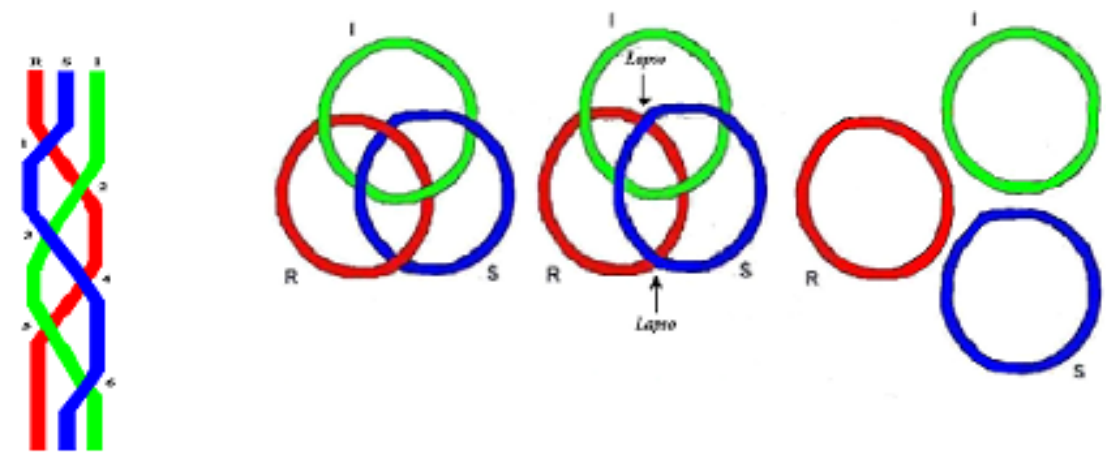

Figura 4 - Dois lapsos no cruzamento do simbólico com o imaginário

Fonte: VORCARO, 2004, p.16 (modificado); LACAN, 1974-1975 (modificado); e SCHEJ TMAN, 2008, p.42 (modificado)

Em maio de 1975, Lacan desenha duas configuraçoes do nó borromeano com dois lapsos ou erros:
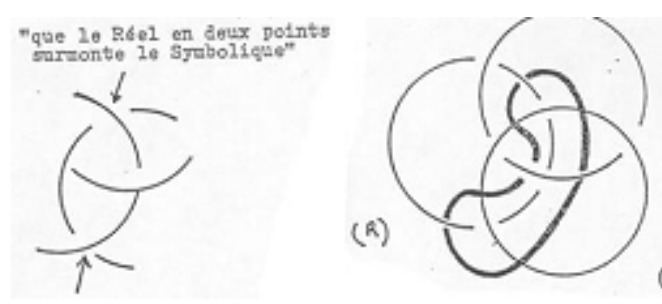

(I)

(s)

Figura 5 - Dois lapsos no cruzamento do real com o simbólico

Fonte: LACAN, 1974-1975/ 2010c

Na primeira figura, o real se superpõe em dois pontos ao simbólico e, na da direita, o simbólico se superpõe ao real. Na segunda figura, os anéis estão soltos e o nó é corrigido pela quarta cordinha de barbante - um quarto elemento que ata os três círculos desatados, permitindo a reparação do nó borromeano com dois erros. Nesse seminário, Lacan ainda não a chama de sinthoma, mas de "figura mais uma", "que se impõe quando se quer fomentar um nó de quatro". Também a chama de "quarto termo", "Complexo de Édipo", "Realidade psíquica" ou "Nome-do-pai", cujo corte fará com que o nó se desate (LACAN, 1974-1975/2010c, tradução nossa). ${ }^{6}$

No Seminário 23 é que ele nomeia esse elemento como sinthoma como na grafia antiga, com h (símbolo, Sigma ' $\Sigma$ '), definindo-o como "o que permite reparar a cadeia borromeana [...] se em dois pontos 
cometermos o que chamei de um erro" (LACAN, 1975-1976/2007, p.90). Ele ainda chama a configuração de "sinthoma borromeano".

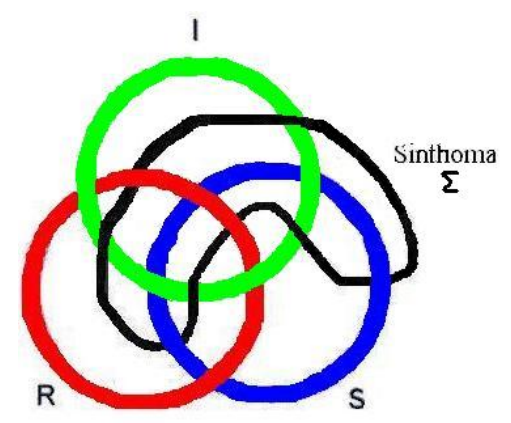

Figura 6 - 0 sinthoma borromeano: três anéis separados ligados pelo sinthoma, pelo quarto [pedaço de barbante] ${ }^{7}$

Fonte: LACAN, 1975-1976/ 2007, p.21 (modificado)

Essa cordinha é trançada engenhosamente sobre os três aros superpostos, dando-Ihes a característica do brasão: se qualquer um deles for cortado, todos se separam. Esse nó não será um nó borromeano, mas "ele se conserva em uma posição tal que tem o aspecto de constituir um nó de três". É o que Lacan já declarara sem pressa (LACAN, 1975-1976/2007, p. 91).

Lendo de forma retroativa os seminários 22 e 23, Schejtman (2008, p.45) propõe este sinthoma borromeano (ou "cadeia borromeana tetrádica"), como base possível da cadeia neurótica, na sua vertente tanto histérica quanto obsessiva. Sem entrar em detalhes sobre a diferença entre essas vertentes, e remetendo o leitor a esse texto ${ }^{8}$, apenas diria que a configuração separada dos registros é insuficiente para mostrar a configuração correta desses tipos clínicos. Precisamente para lidar com os lapsos na trama dos registros é que Lacan vai propor a existência dessa quarta cordinha de barbante, cuja função é a de amarrar o registro solto, dando-lhe o aspecto de nó.

\subsection{Os Nomes-do-pai}

Ainda no final do Seminário 22, apresentando as lições do ano seguinte, Lacan aponta as três nomeações provenientes desses dois erros (ou lapsos) no nó borromeano como os possíveis Nomes-do-pai, já há muito anunciados (LACAN, 1963/2007). Diz: “sobre o que convém dar como substância ao Nome-do-pai: "nominação do imaginário como ini(bi)ção, nominação do real como [...] angústia, ou nominação do simbólico [...] sob a forma de sinthoma" (LACAN, 1975-1976/2010c, p. 189) ${ }^{9}$.

Schejtamn os aponta: 

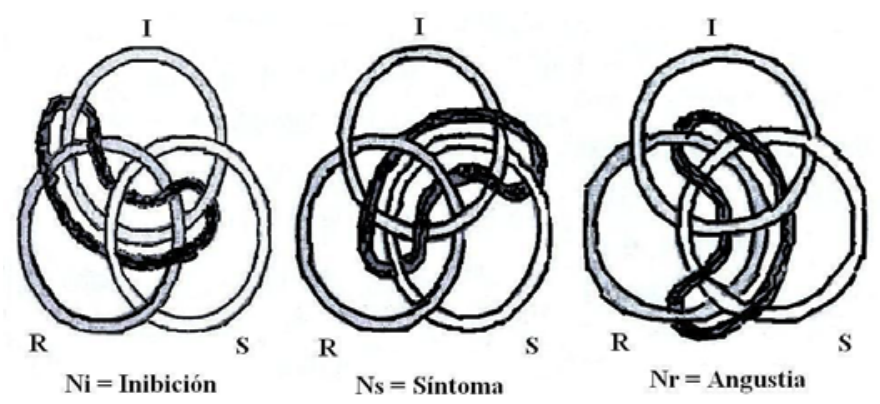

Figura 7: Os Nomes-do pai - I nibição, Sintoma e Angústia Fonte: SCHEJ TMAN, 2008, p.49

Embora Lacan tenha chamado apenas a figura do meio de sinthoma borromeano, de um modo geral, todas podem ser consideradas como contendo reparações sinthomáticas. Isso porque o quarto pedaço de barbante enlaça os anéis nos pontos mesmos em que ocorreram os lapsos. Nos casos acima, o sinthoma enoda, ao mesmo tempo, os dois lapsos, retificando-os, numa ordem diacrônica específica, nos oito pontos de cruzamento. Caso um dos anéis seja rompido, todos se soltam.

\section{Os lapsos na psicose}

\subsection{Na paranóia}

Na lição 6 do Seminário 23, na esteira da pergunta: "Joyce era louco?", Lacan continua a trabalhar com a possibilidade de haver cruzamentos que não resultam em um nó. O que ele propõe "é considerar o caso Joyce como respondendo a um modo de suprir um desenodamento do nó" (LACAN, 1975-1976/2007, p.85). Para que o auditório pudesse acompanhar esse tipo de desenodamento, Lacan o exemplifica com o nó de trevo - o nó a três. Numa lição anterior, esse nó estava colocado na perspectiva da paranoia, com "os três registros em continuidade produzindo emendas nas junturas do real com o imaginário, o imaginário com o simbólico e o simbólico com o real" (SCHEJTMAN, 2008, p.55). Ou, como diz Lacan, "na medida em que um sujeito enoda a três o imaginário, o simbólico e o real, ele é suportado apenas pela continuidade deles. O imaginário, o simbólico e o real são uma única e mesma consistência, e é nisso que consiste a psicose paranóica" (LACAN, 1974-1975/2007, p.52). O nó a três apresenta fenômenos elementares quando não é corrigido. Corrigido, o sujeito pode apresentar uma certa estabilidade. 

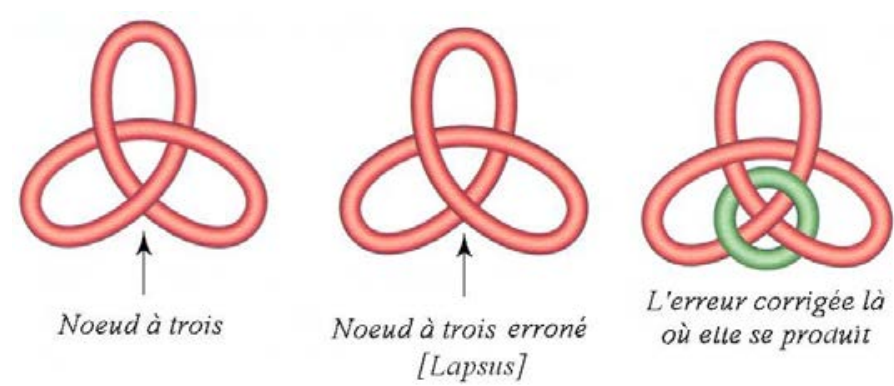

Figura 8 - Nó de três (trevo), nó de três errado [lapso], e o erro corrigido onde ele se produziu

Fonte: LACAN, 2005, p.92, 97

Nesse exemplo, o erro foi corrigido no exato lugar do lapso. Embora o nó que daí resulta seja diferente daquele à esquerda (o nó de três), os três cruzamentos são mantidos.

Nessa mesma lição, Lacan diz que, se o lapso do nó pode ser corrigido no próprio ponto em que o erro se produziu, também é possível corrigi-lo nos outros dois cruzamentos. Aí é evidente que o resultado dessas duas novas correções não manterá o nó de três original (à esquerda na figura 8), tal como a amarração do desenho à direita (figura 8) o fez.
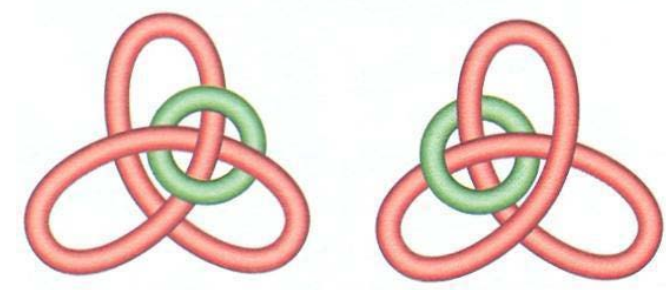

L'erreur étant corrigé aux deux autres points, il ne subsiste vas le même noeud

Figura 9 - 0 erro corrigido em dois outros pontos; não subsiste o mesmo nó

Fonte: LACAN, 2005, p.98

\subsection{Na esquizofrenia}

O raciocínio que vale para a paranoia, no nó de trevo, vale também para o nó borromeano (embora o nó de trevo seja apenas um recorte do nó borromeano nos pontos de cruzamento externo). Na figura 4, podemos ver o barbante passando por baixo do seguimento ao qual deveria superpor-se, produzindo o lapso. Na tentativa de construção de um nó que se pretenderia borromeano, o pedaço de barbante correspondente ao simbólico pode, por exemplo, ao invés de passar duas vezes por baixo do real, tal como no nó borromeano inteiro (figura 1), passar uma vez por baixo e outra por cima (do real). Lacan chama o erro no trançar de lapso. Nesse caso, o nó rateia: 
"Que se dê no lugar onde o nó rateia, onde há uma espécie de lapso do próprio nó, é o que atrai a nossa atenção" (LACAN, 19751976/2007, p.94).

Por exemplo, o simbólico, que deveria passar por baixo do real duas vezes, pode passar apenas uma vez (trançamento 1 da figura 10) e, na hora de passar novamente por baixo (trançamento 4 da figura 10), rateia e passa por cima, como que furando o anel real. Trata-se de um dos lapsos possíveis. Nesse caso, o imaginário se solta em função dessa espécie de furo do simbólico no real. Segundo Schejtman (2008, p.52), essa configuração caracteriza a esquizofrenia, e os chamados fenômenos elementares testemunham o desprendimento do imaginário pela penetração do simbólico no real.
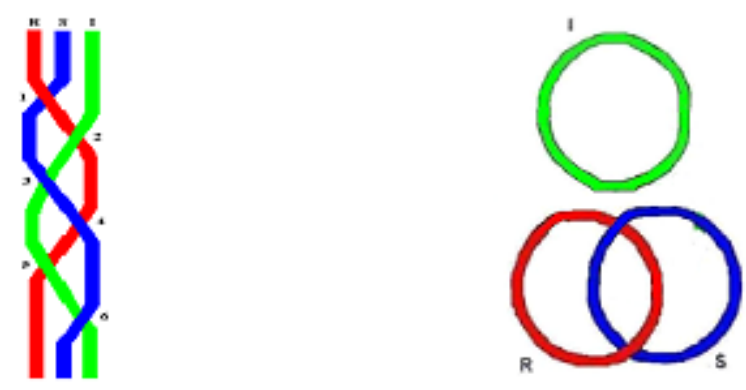

Figura 10 - Esquizofrenia: um lapso no cruzamento do simbólico no real na trança e no nó

Fonte: VORCARO, 2004, p.16 (modificado); SCHEJ TMAN, 2008, p.36 (modificado)

\subsection{Na parafrenia imaginativa}

Schejtman (2008) nos lembra que Miller evocou uma apresentação de paciente de Lacan, a quem resolveu chamar de Sr.a $\mathrm{B}$, considerada parafrênica imaginativa. Em seu texto, Miller (1987) diz que, na apresentação, a plateia, silenciosa, aguarda o diagnóstico. Lacan, que a conduz, não evita fazê-lo. Não se esquiva de dizer "parafrenia" ou "debilidade mental" por medo de "colocar uma etiqueta" em alguém. Quando o quadro clínico lhe permite, ele formula o diagnóstico, mesmo que algo do sentido fique em suspenso. Nas apresentações de paciente que fazia, não havia grandes delirantes. Ali, a "grande psicose", diz Miller (1987, p.164), era rara, e muitos apresentavam apenas um ou outro fenômeno elementar. Para exemplificar, Miller cita uma pessoa atendida por Lacan que, segundo ele, poderia ser incluída entre os "loucos normais". A paciente encontrava-se em uma "flutuação perpétua" que tentava traduzir por uma fórmula notável: "sou interina de mim mesma". Aludindo a Kraepelin, Lacan não hesita em chamá-la de uma parafrênica imaginativa (MILLER, 1987, p.165). Se a debilidade 
consistir em uma não inscrição em um discurso, "ela é débil", diz Miller (1987, p.166).

Toda uma questão relativa às relações do psicótico com a debilidade mental e com o discurso poderia ser aqui discutida. Limitar-nos-emos apenas a apontar que, se o psicótico "é um sujeito fora do discurso, invadido por um gozo desregulado, cujos enunciados principais são holófrases" (MALEVAL, 2000, p.419, tradução nossa) ${ }^{10}$, isso não significa que, fora do discurso, ele se situe fora da linguagem. A Sr. $\underline{\text { a }}$ $B$, tal como Edimundo, encontra-se fora do discurso, incapaz de separar a de a', mas não fora do campo da linguagem.

Além de parafrênica, Miller a considera "hipômona", com "imaginário extraviado sem ego", "espelho enganchado em todas as partes, captado por nada, pura mentalidade desavergonhada" (MILLER, 1987, p.166). Aqui, cabem duas considerações: (1ạ) acompanhando Schejtman, embora realmente ela não tenha "ego", o que se extraviou foi o real; (2a) ela não tem substância, faltando-lhe 0 significante mestre $\mathrm{S} 1$ e o objeto a que preencheria o seu parêntesis, dando-lhe o lastro de sua substância. Schejtman (2008, p.53) sintetiza essa 2a consideração através do matema "i ( )": a Sr. a B é um parêntese vazio, um ser de puro semblante. Suas identificações não se precipitaram em nenhuma cristalização; não há "pessoa", não há "ego".

Não estando submetida à lei simbólica, tanto ela quando Edimundo encontram-se como que extraviados de si mesmos. Embora débeis, cada um trançou o R S I de forma diferente. Vejamos como foi a amarração da Sr.a B. Na figura 10, vimos o simbólico furando o real no cruzamento 4. Outras configurações também são possíveis. 0 lapso pode ocorrer no cruzamento entre o simbólico e o imaginário (figura 3, cruzamento 3). Ao invés de passar por cima, o simbólico pode passar por baixo do imaginário, produzindo um lapso.
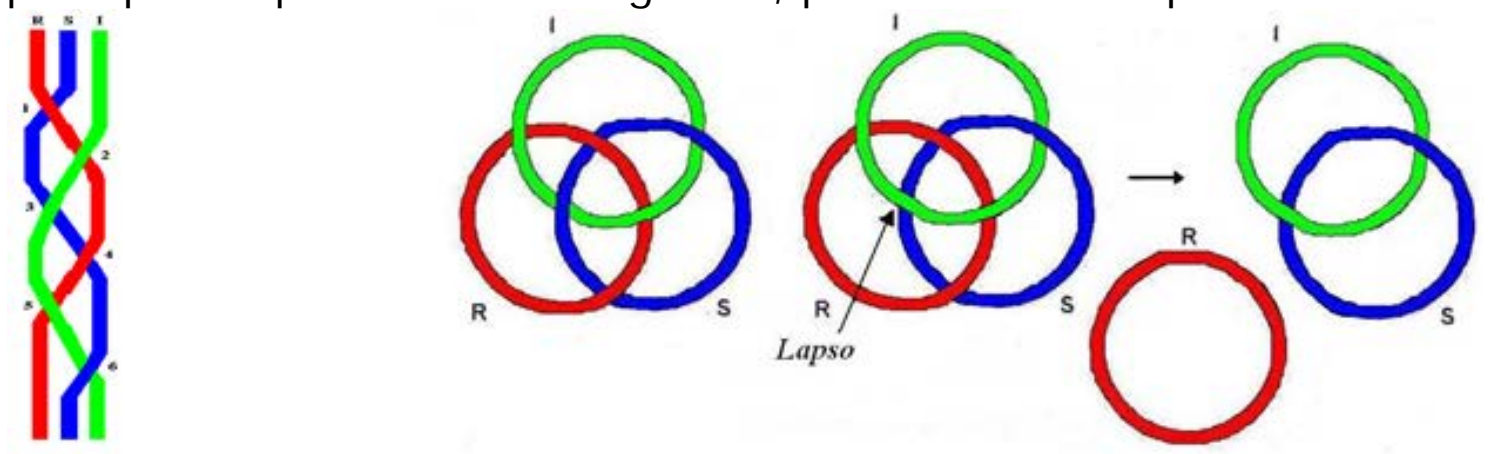

Figura 11 - Parafrenia imaginativa: um lapso no cruzamento do simbólico com o imaginário; na trança e no nó

Fonte: VORCARO, 2004, p.16 (modificado);

SCHEJ TMAN, 2008, p.53 (modificado) 


\subsection{Na psicose maníaco depressiva, na mania e na melancolia}

Já na psicose maníaco depressiva, na mania e na melancolia, Schejtman (2008, p.54) propõe que o lapso ocorre no que chamamos de 20 cruzamento. O real, após cruzar por cima do simbólico, deveria possibilitar a passagem do imaginário por sobre ele, passando, portanto, (o real) por baixo do imaginário. Não é o que ocorre. No cruzamento há um lapso: o imaginário passa por baixo do real. Com isso, o simbólico solta-se, tornando-se empobrecido.
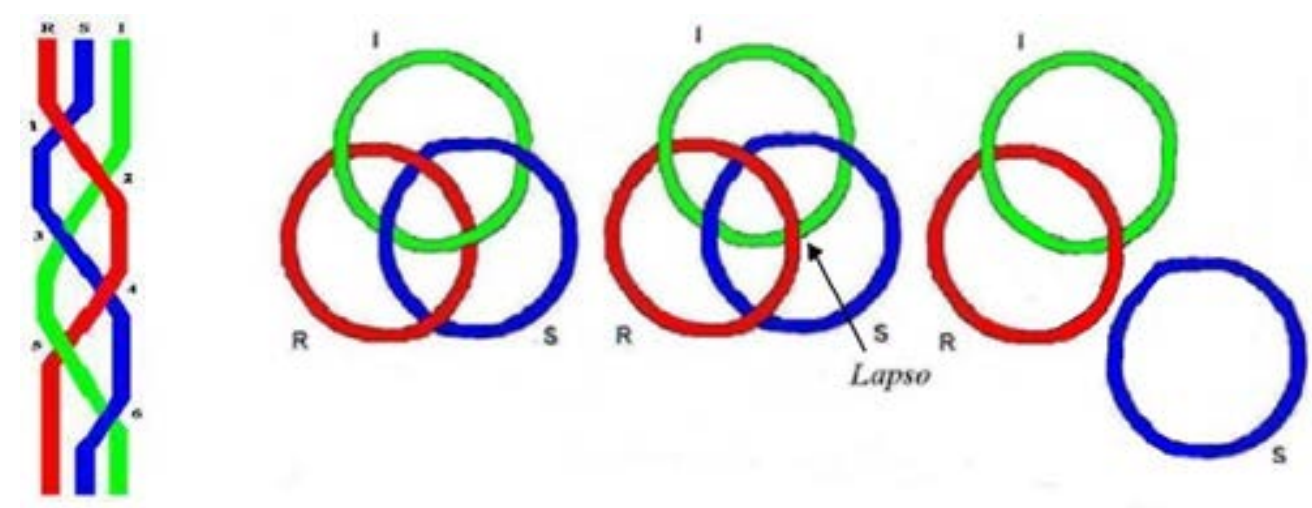

Figura 12 - Psicose maníaco-depressiva, mania e melancolia. Lapso no cruzamento do imaginário com o real; na trança e no nó

Fonte: VORCARO, 2004, p.16 (modificado); SCHEJ TMAN, 2008, p.54 (modificado)

\section{Reparações sinthomáticas e não sinthomáticas}

Assim como consideramos o nó borromeano sem qualquer lapso (figura 1) como algo da ordem do ideal, os três registros completamente separados (figura 4) também nos parece uma configuração ideal.

Com a separação dos registros, Lacan teve de propor a quarta cordinha que repara o(s) lapso(s). Na figura 8, já havíamos dado um exemplo de sinthoma, da cordinha de barbante que corrige, que repara o erro do nó de três (trevo). Entretanto, nem todos os pedaços de barbante que corrigem um lapso podem ser chamados de sinthoma. Há reparações que corrigem o lapso precisamente no lugar do cruzamento onde o lapso se deu, e há aquelas que corrigem em outros lugares. Se a figura 8 apresenta uma reparação sinthomática estabilizadora, há reparações não sinthomáticas, que enlaçam lugares onde o lapso não aconteceu. A figura 9 exemplifica isso, apontando para a existência de outros nós, isto é, de soluções não sinthomáticas e mesmo não estabilizadoras.

A reparação sinthomática tem, pois, de reparar o nó no ponto mesmo em que houve o lapso, e a não sinthomática será a reparação em um 
cruzamento que não é aquele onde o lapso ocorreu. Se não há a reparação, um dos anéis se solta e certamente encontraremos fenômenos elementares. Se há uma amarração não sinthomática, haverá certa estabilidade, mas muito insatisfatória. A presença do analista pode possibilitar que uma amarração não sinthomática seja revertida em sinthomática, embora não seja possível conseguir-se uma amarração borromeana.

Tendo, pois, feito todas essas considerações, podemos finalmente nos perguntar: qual seria a amarração de Edimundo?

\section{Edimundo e a psicose}

Edimundo foracluiu o Nome-do-pai. Embora carente de fantasia fundamental e da função do traço unário, não é invadido pelo gozo desordenado típico dos fenômenos elementares. Também não apresenta as holófrases típicas da debilidade mental, caracterizadas por uma locução na qual o sujeito, o verbo e os complementos são condensados em uma só palavra. Nelas o sujeito é confundido com a sua mensagem, e o enunciado e a enunciação são homogêneos. No caso da debilidade mental, "o débil, de maneira caricatural, repete os enunciados dos outros para falar de si mesmo" (SANTIAGO, 2005, p.166).

Não é o caso de Edimundo. Se ele goza na repetição em todas as sessões de seu bordão, de seu puro S1: "Sou um homem direito", isso está muito mais para uma impossibilidade de abertura dialética ao Outro do que para holófrases do tipo "fizcacama", "goiafafá" ou assemelhados. Nessa repetição infindável, pode-se perceber a fixação e a solidificação do S1 primordial, separado do S2, sem articulação na cadeia simbólica. É nesse sentido que se pode tomar tal S1 como sozinho, como holófrase psicótica e não débil, tal como diagnosticado na escola infantil. Aqui, por estar fora do discurso, não há divisão do sujeito pelo significante, que não aparece entre S1 e S2, nem há a possibilidade da produção de uma enunciação possível. Edimundo, por outro lado, não é invadido pelo gozo desordenado, pois consegue erguer uma barreira. Para isso, o preço a pagar foi a debilidade mental, não caracterizada pelas holófrases psicóticas, mas pela impossibilidade de ler e de escrever.

Nesse sentido, Edimundo aponta para a relação estabelecida por Lacan entre a holófrase e a debilidade mental. Quando não há intervalo entre S1 e S2 [holófrase], diz Lacan, "quando a primeira dupla de significantes se solidifica, se holofraseia, temos o modelo de toda uma série de casos" [...]. Ao se referir à criança débil como que reduzida ao lugar do $\mathrm{S}$ no quadro abaixo à direita, isto é, como não podendo ser nada além de um suporte do desejo obscuro de sua mãe, Lacan diz que "aí se introduz, na educação do débil, a dimensão 
do psicótico". [...] "É certamente algo da mesma ordem do que se trata na psicose" (LACAN, 1964/1979, p.225).

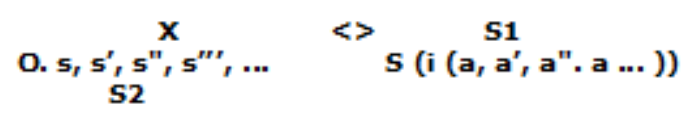

Figura 13 - Quadro da alteração dos pontos de referência imaginários na holófrase ${ }^{11}$ O. S, s', s", s'"...: Série dos sentidos i (a, a'. a" a"', ...) : Série das identificações

Fonte: LACAN, 1964/ 1979, p.224

A impossibilidade de Edimundo extrair o objeto a acaba por predispôlo a ser gozado pelo Outro, mas não no nível do delírio, da invasão de um gozo louco. A contenção, como dito, é feita ao preço da debilidade mental.

\subsection{A amarração de Edimundo}

A solução que Edimundo adota seria uma solução semelhante à de Joyce? Ao considerá-lo um psicótico ordinário, poderíamos supor uma amarração como a de Joyce? Seria essa a configuração do nó de Edimundo? Como Edimundo restaurou as falhas do lapso? Certamente foi pela debilidade mental, constatada por testes psicométricos, que não foram capazes, entretanto, de apontar seu caráter de suplência de uma psicose. Mas, como Joyce, ele também possuiria um ego reparador?

$\mathrm{Na}$ figura 10, mostramos a esquizofrenia como o resultado de um lapso no cruzamento do simbólico com o real. Como afirma Schejtman, "Os chamados fenômenos elementares em cruz entre os registros, tão prevalentes na esquizofrenia, testemunham essa interpenetração" (SCHEJTMAN, 2008, p.53). Ora, salvo em raras ocasiões, Edimundo não apresenta fenômenos elementares. Com isso, pode-se considerar que, embora se pudesse esperar que o imaginário estivesse solto, constata-se que não está, devido à ausência de fenômenos elementares. Tanto no seu caso, quanto no de Joyce, houve o lapso esquizofrênico, mas a sua forma de reparar não foi a mesma de Joyce. 


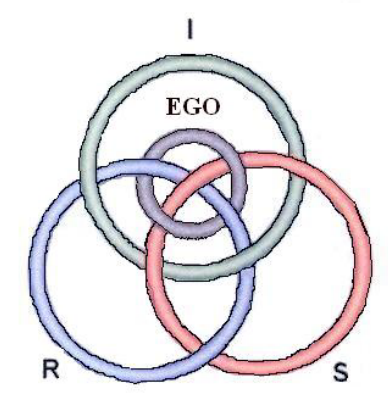

Figura 14 - O ego que corrige o lapso no caso de J oyce Fonte: LACAN, 1975-1976/ 2005, p. 152 (modificado)

Para Lacan, Joyce é psicótico, mas isso não significa que a sua realidade psíquica seja a da figura 10 . 0 imaginário não está solto. Se Lacan definira o sinthoma como a reparação na cadeia borromeana que portaria dois pontos de erro ou lapso, para a construção do caso J oyce ele precisará estender o conceito para a correção não de dois, mas de apenas um lapso. Vai chamar de sinthoma o ego que corrige as amarrações de Joyce, o sant'homem - sin-t'homa madaquim "há o sinthoma madaquin, que escrevo como vocês quiserem" (LACAN, 1975-1976/2010c, p.14, tradução nossa) ${ }^{12}$. Joyce é, pois, esse artista que, inspirado nos três princípios estéticos de Santo Thomas de Aquino, na intégritas, na consonantia e na claritas, toma-os como base da estética de suas epifanias.

Para Lacan, embora o nó de Joyce tenha apenas um lapso, a sua estabilidade foi conseguida através de um pai, esse quarto elemento "sem o qual nada é possível no nó do simbólico, do imaginário e do real". Mas, além de chamá-lo pai, Lacan diz que "há um outro modo de chamá-lo. É nisso que o que diz respeito ao Nome-do-pai, no grau em que Joyce testemunha isso, eu o revisto hoje com o que é conveniente chamar de sinthoma" (LACAN, 1975-1976/2007, p.163). Mas, há que se apontar que tal sinthoma não deve ser confundido com o sinthoma borromeano, tal como na neurose. Se a amarração foi feita para reparar um lapso, mesmo que haja uma estabilização através de um quarto barbante, o nó daí resultante não será borromeano, pois um dos elementos sempre como que irá furar uma das rodinhas. O que não acontece, evidentemente, com o sinthoma borromeano. Lacan vai chamar, no caso específico de Joyce, tal sinthoma de "ego"; o ego que corrige o erro, a falha, o lapso, dandoIhe a estabilidade que lhe permitiu escrever o que muitos críticos consideram um dos mais importantes romances do século XX: Ulisses.

Embora não seja borromeano, isso não significa que não possa haver, no nó, a correção do erro. Tal reparação é o chamado ego de Joyce, a escrita que the é essencial (LACAN, 1975-1976/2007, p.143). Podese notar que, na figura anterior, o ego, enquanto reparação do nó, 
incide exatamente no lugar onde a falha ocorreu. É por isso que Joyce encontrou a sua estabilização. Caso a reparação houvesse ocorrido, por exemplo, enlaçando o imaginário ao real, a configuração seria nitidamente não sinthomática. A reparação ter-se-ia dado em outro lugar que não onde o lapso originalmente se dera.

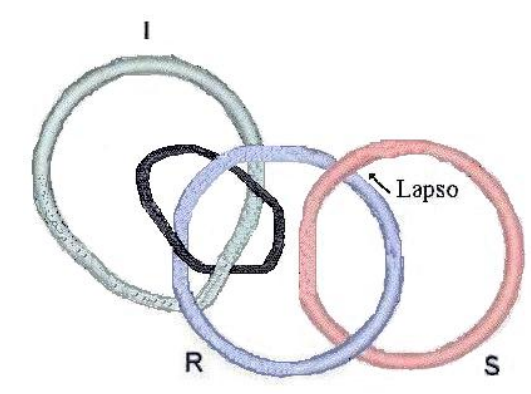

Figura 15 - Reparação não sinthomática

Aqui, embora haja uma estrutura psicótica, não há desencadeamento. Porém, não há, tampouco, uma saída edípica satisfatória.

Retomando, teria Edimundo conseguido a sua estabilidade através da constituição de um ego capaz de fazer suplência à precária amarração dos registros?

Não consideramos que a constituição de um ego de tipo joyceano tenha sido a solução que ele deu à precariedade de sua amarração. A configuração do nó é diferente daquela de Joyce. Se formos figurá-la em termos da teoria dos nós, provavelmente poderemos supor que o nó imaginário não se encontra articulado aos outros, como é típico na esquizofrenia. Mas isso não significa que ele esteja solto, como ilustrado na figura 10, pois, como foi dito, Edimundo não apresenta fenômenos elementares, salvo, talvez, um desencadeamento momentâneo do nó por ocasião de sua prisão. Isso significa que, de alguma forma, ele foi capaz de amarrar, a seu jeito, os três registros. Em termos de trança, quando não há a amarração normal e o simbólico fura o real (lapso), temos a seguinte configuração: 

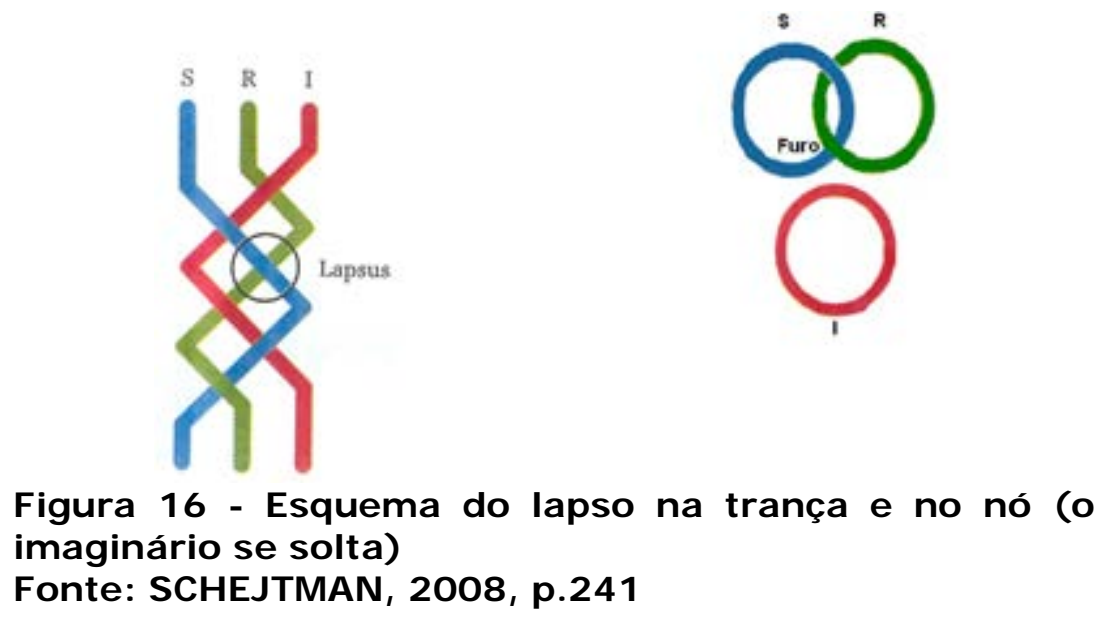

Não nos parece, entretanto, que o imaginário de Edimundo esteja solto. Não parece tampouco que ele tenha amarrado os registros através de um ego estabilizador do tipo de Joyce, tal como Schejtman (2008, p.236) apresenta:
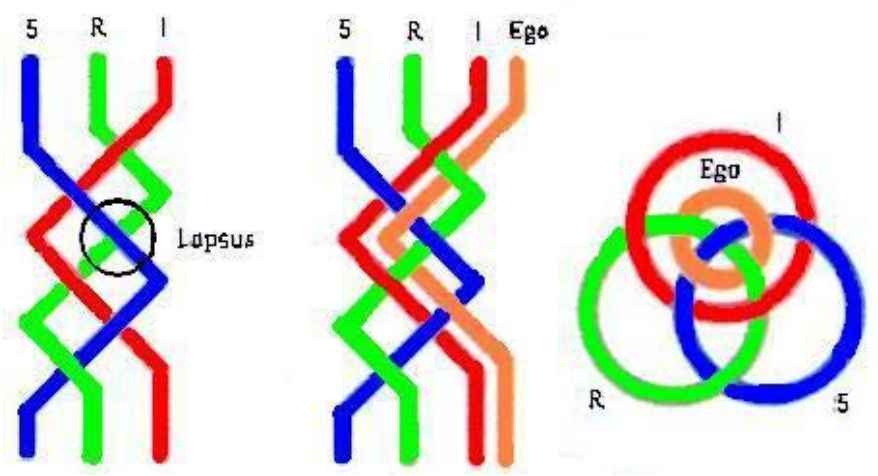

Figura 17 - A reparação da trança de J oyce Fonte: SCHEJ TMAN, 2008, p. 236

Não foi essa a sua forma de fazer suplência à carência do Nome-dopai. Se isso tivesse acontecido, certamente ele poderia ter encontrado alguma outra solução, que não a de repetir incessantemente a sua história: "não tenho emprego"; "divido de forma indevida a minha aposentadoria", etc. Certamente, teria aprendido a ler e a escrever, e não apresentaria os motivos que o conduziram à prisão. Quando, na Clínica de Psicologia, foi encaminhado a um estagiário de psicanálise, ele já havia sido atendido em outras abordagens. O erro de leitura da mensagem, para aqueles estagiários, foi o de considerar tais frases como queixas. Infelizmente, não eram. Qual poderia ser, então, o seu sentido?

Embora a expectativa dos estagiários anteriores fosse a de reinseri-lo na cadeia produtiva, na cadeia da normalidade, torná-lo norma-I (norme-mâle) ou adaptado à norma masculina ou fálica, como se ele tivesse recalcado o Nome-do-pai, tal não nos parece ser a 
preocupação maior de Edimundo. A hipótese que sustenta esse trabalho é a de que, antes do encontro com um praticante de psicanálise, ele se esforçava para manter a estabilização que conseguiu, sustentando uma posição de debilidade não sinthomática através de uma pouco satisfatória reparação em forma de nãosinthoma-cacho de debilidade mental.

Essa estabilidade muito insatisfatória e precária da psicose de Edimundo foi conseguida através do não-sinthoma-cacho de sua debilidade mental. $O$ tratamento Ihe tem possibilitado tentar transformar esse nó não sinthomático em sinthomático, embora jamais venha a ser um sinthoma borromeano, operação impossível, tendo em vista a foraclusão do Nome-do-pai. Tal solução integra de maneira mais satisfatória, embora não borromeana, os três registros.

Essa hipótese desdobra-se nos seguintes pontos: (1) Edimundo é psicótico; (2) Sua psicose é comum (ordinária), isto é, não acompanhada de fenômenos elementares, embora esses possam ocasionalmente ocorrer quando de um breve desenodamento do quarto laço; (3) a não apresentação de fenômenos elementares devese à sua forma particular de amarração; (4) essa amarração é um não-sinthoma-cacho; (5) é esse não-sinthoma que lhe possibilita uma "certa estabilidade na trança" (SCHEJTMAN, 2008, p.242); (6) essa estabilidade foi conseguida à custa de uma debilidade mental, representada no esquema a seguir (Figura 18) pelo nó azul - solto do conjunto, embora a ele ligado pelo lapso (furo) no Real; (7) caso Edimundo não se tivesse estabilizado através desse não-sinhtomacacho, possivelmente, no lugar da debilidade mental - sua forma singular de defesa -, ele teria desencadeado uma psicose com fenômenos elementares; (8) com as sessões de psicanálise aplicada, Edimundo está no processo de amarrar a sua trança de uma outra maneira, que poderá transformá-la de não sinthomática em sinthomática; (9) isso faz com que o simbólico, antes agarrado à trama do nó por um frágil lapso com o real, furando-o, seja incorporado à trama sinthomática por tentativas, ensaios de elaboração de um sinthoma-cacho, mais estabilizador. Se isso não houvesse ocorrido, ele se teria mantido da mesma maneira como se portou durante seus sessenta e poucos anos, vivendo uma vida aparentemente normal, embora débil, isto é, incapaz de aprender a ler e a escrever.

Até começar com o trabalho da análise, Edmundo estava estabilizado, mesmo que precariamente. Não se tratava, evidentemente, de uma estabilização tipo ego de Joyce, pois a solução dada por ele era a de uma debilidade mental. Em algum momento de sua constituição como sujeito, o Simbólico de Edimundo como que furou o campo do Real, produzindo um lapso (figura 16). Como consequência, o Imaginário só pôde enlaçar-se na estrutura Real/Simbólico através do não-sinthoma-cacho (boucle) - no seu caso, através da debilidade 
mental. Isso sempre o impossibilitou de se alfabetizar, fazendo-o repetir-se, provavelmente, em todos os seus encontros com os educadores.

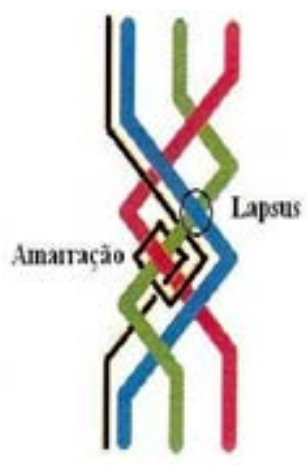

Legenda:

*não-sinthoma

* Simbólico

$*$ Real

* I maginário

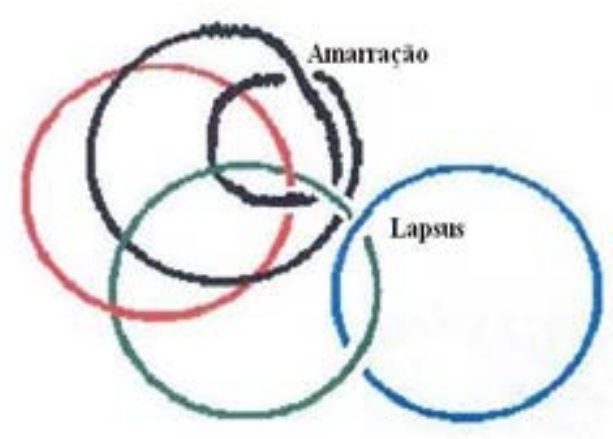

Figura 18 - Esquemas não-sinthoma-cacho ${ }^{13}$ em formato de trança e de nó ${ }^{14}$ Fonte: SCHEJ TMAN, 2008, p.242 (modificado)

Se, durante toda a sua vida, Edimundo manteve-se nessa posição débil, com o tratamento por uma praticante de psicanálise na Clínica, de uma instituição de ensino superior, foi possível constituir, a cada encontro, um S1 que lhe tem possibilitado, aos poucos, testar novas formas de amarração, como esta:
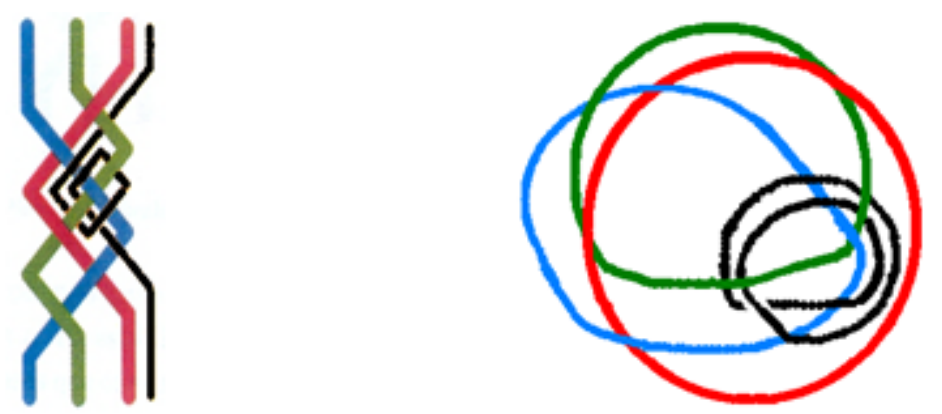

Figura 19 - Esquemas Sinthoma-cacho em formato de trança e de nó Fonte: SCHEJ TMAN, 2008, p. 241

A hipótese que está sendo considerada é a de que a debilidade de Edimundo, enquanto não-sinthoma-cacho (bucle), pode deixar de ser a sua única forma de amarração. Parece-nos que ela vem sendo substituída por um sinthoma-cacho (bucle), mais estabilizador. No momento, a cada sessão, a 4 a corda muda a amarração original, 
incapaz de reparar o lapso posto que se encontrava como que fora de lugar, passando, então a enlaçar os registros no ponto mesmo do lapso. Isso dá a Edimundo um tipo de estabilidade, ainda que precária, diferente da que apresentava quando encontrou a psicanálise. Essa estabilidade, embora momentânea, é sempre desfeita algum tempo após a sessão, mas ele a refaz, como Penélope, semana após semana.

A hipótese que fazemos é no sentido de que, caso esse trabalho não fosse feito, o Imaginário ver-se-ia novamente às voltas com a amarração débil, ou mesmo poderia soltar-se momentaneamente, provocando um episódio alucinatório, como o que pode ter ocorrido na saída do bordel anos atrás. Até que esse cacho se estabilize em forma de broche de saber (se é que isso vai acontecer), é necessária a presença de alguém que o escute e que lhe franqueie as possibilidades de sustentação de uma nova amarração, e isso sem as exigências que a pedagogia ou uma psicoterapia lhe imporiam.

No atendimento da praticante de psicanálise, não se encontram presentes quaisquer exigências de que ele se alfabetize ou mesmo que encontre um trabalho. Com isso, o imaginário pode amarrar-se de uma outra forma. Não nos parece que ele estivesse interessado em demandar aos mais diversos estagiários aos quais foi encaminhado, por tantos e tantos anos, uma solução pragmática. Ele não requer do praticante soluções que envolvam valores tais como eficiência ou produtividade. Ele se encontra satisfeito com o seu modo de vida, com a solução encontrada. A ida à Clínica permite-Ihe a estabilidade do homem direito ao qual mantém a sua fidelidade.

Numa das últimas sessões de outubro passado, ele relata um fato (realmente?) acontecido há algum tempo. Ele se encontrava num ônibus que foi parado em uma barreira policial. Edimundo conseguiu manter-se calmo na hora em que um policial o abordou dentro do ônibus. Ele localiza esse episódio no sábado anterior, mas não se tem certeza de que isso tenha realmente ocorrido, pois foi dito com muitas hesitações e tropeços. Relata a praticante:

Edimundo conta que, no sábado, ia para a casa da namorada quando o ônibus onde estava foi interceptado pela polícia... Diz que, tempos atrás, ficaria muito nervoso e não sabe o que poderia ter acontecido. Lembra-se de quando ficou preso e de que a sua família não foi comunicada sobre seu paradeiro. Dessa vez, porém, conseguiu... manter a calma. Conclui dizendo que foi tratado com educação pelos policiais, que não o incomodaram. Eles saíram e o ônibus prosseguiu com o seu trajeto.

Não houve maiores consequências.

Esse relato é bem parecido com o de sua prisão, mas a posição de Edimundo foi, sem dúvida, uma posição bem diferente. Dessa vez ele soube, de alguma forma, lidar com a situação. 


\section{Conclusão}

A solução e o suporte fornecidos pela debilidade de Edimundo ilustram o trabalho incansável do pequeno astuto mencionado por Lacan (1968-1969/2008) no Seminário 16 e que, nesse caso, evidencia-se pela tarefa de sustentar a consistência do Outro na holófrase. Assim, ele constitui ou mesmo restitui o estatuto do Um, o S1, no instante eterno de uma existência, corpo não fundido ao de sua mãe, mas a ele mesmo, não permitindo o surgimento do sujeito atravessado pela falta. A função da causa encontra-se inibida ou foracluída e a fixidez de sua posição subjetiva assegura o desabonamento do inconsciente.

Edimundo, antes de ir à Clínica, estava estabilizado em sua debilidade mental que fazia uma espécie de suplência para a sua psicose. A questão que se levantou foi, em termos de nós, como seria a sua configuração ao chegar à Clínica. Descartamos de imediato a possibilidade de tratar-se de um sinthoma borromeano (que pressupõe o Nome-do-pai). Qual seria, então, a formatação do nó de sua debilidade? Sugerimos tratar-se inicialmente de um nãosinthoma-cacho, no qual havia uma amarração. Ao invés da incidência da fissura real da equivalência simbólica, o que ocorreu foi justamente o oposto: o simbólico encobriu a fissura real. Nesse caso, como no das psicoses desencadeadas, o registro imaginário poderia ter-se soltado, mas isso não foi o que de fato ocorreu. O não sinthoma manteve o imaginário enlaçado ao real e, em última instância, também ao simbólico, que se amarrou ao nó apenas por sua articulação com o real, que o "fura". Tal operação parece ter impedido a ocorrência de fenômenos elementares, ao preço de uma debilidade mental. Essa forma de nó não é sinthomática porque a amarração não se fez no lugar onde se deu o lapso.

O tratamento na Clínica tem possibilitado que ele ensaie transformar o nó não sinthomático em nó sinthomático, articulando o simbólico ao imaginário e ao real, o que Ihe dá uma maior liberdade em relação à sua debilidade. Não chega a possibilitar a transformação do sinthoma cacho em um sinthoma borromeano, o que seria impossível, tendo em vista a foraclusão do Nome-do- pai. Com isso, entretanto, ele agora parece ter a chance de amarrar a trança do RSI de uma outra forma, o que é sinal da possibilidade de um broche de saber.

Edimundo ainda frequenta semanalmente a Clínica. Mais apaziguado, continua vivendo de sua pensão e sempre manifesta o desejo de trabalhar com carteira assinada. Agora, entretanto, ele parece saber como melhor lidar com a sua vida, com os policiais e com a lei. 


\section{Referências}

ALVARENGA, E. O paradigma Lol V. Stein. Almanaque de psicanálise e saúde mental, v. 5, n. 8, 2020, p. 57-66, 2002.

DURAS, M. O Deslumbramento (le ravissement de Lol v. Stein). Tradução: Ana Maria Falcão. Rio de Janeiro: Nova Fronteira, 1986.

FREUD, S. Notas psicanalíticas sobre um relato autobiográfico de um caso de paranoia (Dementia Paranoides) (1911). In: Edição Standard Brasileira das Obras Psicológicas Completas de Sigmund Freud. Rio de J aneiro: I mago, v. 12, 1977.

IRMA. La psychose ordinaire; la Convention d'Antibes. Paris: Le Seuil, 1999.

LACAN, J. O Seminário, livro 3, as psicoses (1955-1956). Rio de Janeiro: Ed. Zahar, 1985.

. Le Séminaire de Lacan, livre $\mathbf{1 0}$ bis - Les Noms-du-

père (20-11-1963).

Disponível

em:

<http://gaogoa.free.fr/Seminaires.htm>. Acesso em: 15 jun. 2007.

. O Seminário, livro 11 - Os quatro conceitos fundamentais da psicanálise. Tradução: M. D. Magno. Rio de Janeiro: Zahar, 1964/1979.

O Seminário, livro 16, De um Outro ao outro (19681969). Rio de Janeiro: Ed. Zahar, 2008.

Le Séminaire de Lacan, livre 19 - ... Ou Pire (1971$\overline{1} \overline{9} \overline{2} \overline{/} \overline{2} 010 \mathrm{a})$.

Disponível

em:

<http://gaogoa.free.fr/Seminaires_HTML/19-OP/OP09021972.htm>.

Acesso em: 17 jul. 2010.

Le Séminaire de Lacan, livre 19 b - Le savoir du psychanalyste (1971-1972/2010b). Disponível em: <http://gaogoa.free.fr/Seminaires_HTML/19bis-

SP/SP06011972.htm>. Acesso em 18 jul. 2010.

errent (1972-1973/2009). Disponível em: <http://gaogoa.free.fr/SeminaireS.htm>. Acesso em: 8 nov. 2009.

$\overline{1} \overline{9} \overline{5}-\mathbf{L}$ Le Séminaire de Lacan, livre 22 - R.S.I (1974<http://gaogoa.free.fr/Seminaires.htm>. Acesso em: 18 jul. 2010.

Le Séminaire, Iv. 23, Le sinthome (1975-1976). In: Miller. J-A. (Ed.). Paris: du Seuil, 2005.

O Seminário, livro 23, O Sinthoma (1975-1976). In: Miller. J-A. (Ed.). Rio de Janeiro: Jorge Zahar, 2007.

LAURENT, E. Versões da clínica psicanalítica. Rio de Janeiro: J orge Zahar, 1995.

LAURENT, E. "Las psicosis ordinarias". Disponível em: <http://elpsicoanalistalector. blogspot.com/2007/09/eric-laurent-laspsicosis-ordinarias.html>. Acesso em: 03 out. 2009. (Conferência originalmente proferida em Buenos Aires em 07/11/2006) 
MALEVAL, Jean-Claude. La foraclusion du Nom-du-père: le concept et sa clinique. Paris: le Seuil, 2000.

MILLER, J-A. Enseñanzas de la presentation de enfermos. In: Matemas I. Tradução: Carlos A. de Santos, 189. Buenos Aires: Manantial, 1987.

SANTIAGO, A. L. A inibição intelectual na psicanálise. Rio de J aneiro: J orge Zahar, 2005.

SCHEJTMAN, F. Síntoma y sinthoma. In: Ancla, v. 2, 2008, p. 1559.

- Introducción de la trenza. In: Ancla, 2 (encadenamientos y desencadenamientos), p. 211-267, 2008.

VORCARO, A. A criança na clínica psicanalítica. Rio de Janeiro: Companhia de Freud, 2004.

\title{
Endereço para correspondência Luis Flávio Silva Couto
}

Rua Teixeira de Freitas 178, apto 702

CEP: 30.350-180 - Belo Horizonte, Minas Gerais - Brasil

Endereço eletrônico: luisflaviocouto@terra.com.br

Recebido em: 28/09/2010

Reformulado em: 12/05/2011

Aceito para publicação em: 30/05/2011

Acompanhamento do processo editorial: Rita Maria Manso de Barros

\begin{abstract}
Notas
*Psicólogo, Psicanalista, Doutor em Filosofia pela UFRJ, Pós-doutorado em psicanálise pela Université Paris 8, Membro da Escola Brasileira de Psicanálise Seção Minas da Associação Mundial de Psicanálise e Professor da PUC Minas.

${ }^{1}$ Texto apresentado na Mesa simultânea II - A: Psicose do XVI Encontro Internacional do Campo Freudiano (ENAPaOL) Buenos Aires, 28/11/2009.

2“"El programa de investigación llamado abordar la clínica a partir de las psicosis ordinaria, es tratar de establecer una cierta pragmática caso por caso de cómo en un sujeto vienen a abrocharse las consistencias de lo real, simbólico, imaginario, como el sujeto viene a interpretar los acontecimientos del cuerpo que le llegan, como sitúa la fuga del sentido, como hace con la dispersión de lo imaginario en la desmembración fundamental, como trata de recurrir entonces a normas más o menos establecidas para apoyarse en la construcción de algo" (LAURENT, 2006).

3“la psychose compensée, la psychose supplémentée, la psychose non-déclenchée, la psychose médiquée, la psychose em thérapie, la psychose em analyse, la psychose qui évolue, la psychose sinthomée" (MILLER, 1999, p. 230).

4"une chaîne de trois, et tel qu'à détacher un des anneaux de cette chaîne, les deux autres ne peuvent plus un seul instant tenir ensemble" (LACAN, 1972/2010b, p. 71).

5“ces trois indications de sens, de sens matérialisé qui se figure dans les nominations du Symbolique, de I'Imaginaire et du Réel" (LACAN, 13-051975/2010c, p. 182).
\end{abstract}


"'la figure qui s'impose quand on veut fomenter un noeud à quatre" (LACAN, 1305-1975/2010, 182.)

${ }^{7} \mathrm{Em}$ relação à trança, no Seminário 23 , ver um exemplo muito intricado relativo ao nó borromeano de quatro nós de três (LACAN, 16-12-1975, p.46).

${ }^{8} \mathrm{Em}$ relação às articulações do sinthoma borromeano com as neuroses, ver também o curso "El sinthoma em las neurosis: Abordajes de las neurosis em el última período de la obra de Lacan (1974-1981) de Fabián Dario Schejtman e Cláudio Godoy na Universidade de Buenos Aires (UBACyT P0 22) ano 2008-2010.

9“nomination de l'Imaginaire comme inhi(bi)tion, nomination du Réel comme [...] angoisse, ou nomination du Symbolique [...] sous la forme du Symptôme, [...] sur ce qu'il convient de donner comme substance au Nom du Père" (LACAN, 13-051975, p.189).

10“un sujet hors discours, envahi para une jouissance dérégulée, dont les énoncés majeurs sont holófrasés" (MALEVAL, 2000, p.419).

${ }^{11}$ Sem tecer maiores comentários e apenas para enriquecer o texto, aponto duas outras versões dos pontos de referência imaginários do Seminário 11, uma da lição 10 e outra da lição de 17 de junho de 1964. Confira em <http://gaogoa.free. fr/SeminaireS. htm>.

12“Il y a Le sinthome madaquin, que j'écris comme vous voudrez (LACAN, 19751976/2010a, p. 14). N. T. Utilizei o original porque a versão em português está "masdiaquino".

${ }^{13}$ Representada no esquema (Figura 18 ) pelo nó azul - solto do conjunto, embora a ele ligado pelo lapso (furo) no Real. Aqui, pode-se notar o Simbólico sem amarração, apenas furando o Real.

${ }^{14}$ Para melhor visualização, a cor do sinthoma foi trocada de amarela (no original de Fabian) para preta. No desenho, pode-se notar que se trata de um não-sinthoma, pois a corda amarra em um local diferente de onde o lapso ocorreu. 